\title{
cappuccino and spire: two unique maternal-effect loci required for both the anteroposterior and dorsoventral patterns of the Drosophila embryo
}

\author{
Lynn J. Manseau and Trudi Schüpbach \\ Department of Biology, Princeton University, Princeton, New Jersey 08544 USA
}

\begin{abstract}
cappuccino and spire are unique Drosophila maternal-effect loci that participate in pattern formation in both the anteroposterior and dorsoventral axes of the early embryo. Mutant females produce embryos lacking pole cells, polar granules, and normal abdominal segmentation. They share these defects with the posterior group of maternal-effect genes. Although embryos are defective in abdominal segmentation, in double mutant combinations with Bicaudal $D$, abdominal segments can be formed in the anterior half of the egg. This indicates that embryos produced by mutant females contain the 'posterior determinant' required for abdominal segmentation (Nüsslein-Volhard et al. 1987) and suggests that the wild-type gene products are not required for production of the posterior determinant but, rather, for its localization or stabilization. The vasa protein, a component of polar granules, is not localized at the posterior pole of mutant egg chambers or embryos, providing additional support for the hypothesis that localization to or stabilization of substances at the posterior pole of the egg chamber is defective in mutant females. Females mutant for the strongest alleles also produce dorsalized embryos. Phenotypic analysis reveals that these dorsalized embryos also have abdominal segmentation defects. The mutant phenotypes can be ordered in a series of increasing severity. Pole cell formation is most sensitive to loss of functional gene products, followed by abdominal segmentation, whereas normal dorsoventral patterning is the least sensitive to loss of functional gene products. In addition, mutant females contain egg chambers that appear to be dorsalized, resulting in the production of eggs with dorsalized eggshells. Germ-line mosaics indicate that cappuccino and spire are required in the oocyte-nurse cell complex. This suggests that the eggshell phenotype results from altered pattern in the underlying germ cell. Also, we defined the epistatic relationships between several early patterning loci, on the basis of an analysis of the eggs and embryos produced by females doubly mutant for cappuccino or spire and other loci that affect the pattern of both the egg and the embryo. On the basis of our current knowledge of the genes involved in this process, we formulated a working model for the early steps in dorsoventral patterning.
\end{abstract}

[Key Words: Drosophila; cappuccino; spire; maternal effect; grandchildless-knirps; oogenesis]

Received April 11, 1989; revised version accepted June 16, 1989.

Both the eggshell and embryo of Drosophila are asymmetric. The egg possesses a flat dorsal surface, a rounded ventral surface, a micropyle and operculum at the anterior end, and two chorionic appendages located anterodorsally. These asymmetric features of the egg become visible during the later stages of oogenesis. Earlier in oogenesis, the follicle cells, which surround the developing oocyte and secrete the eggshell, show an asymmetric distribution along the dorsoventral axis with respect to cell shape and density (King 1970). Within the embryo, the pattern of early zygotic gene expression is asymmetric both in the anteroposterior and dorsoventral axes. Localized gene expression along the anteroposterior axis of the embryo results in the formation of a series of segmentally repeated units with the head at one end and the telson at the other (for reviews, see Scott and O'Farrell 1986; Akam 1987; Ingham 1988). Along the embryonic dorsoventral axis, asymmetric gene expression leads to the formation of the mesoderm ventrally with the neurogenic ectoderm, the dorsal ectoderm, and the amnioserosa forming progressively more dorsally (Doyle et al. 1986; St. Johnston and Gelbart 1987; Steward et al. 1988; Thisse et al. 1988; for reviews, see Anderson 1987; Levine 1988).

The asymmetries observed in eggs and embryos are specified genetically. Numerous maternal-effect loci have been identified that function in the production of either the dorsoventral or anteroposterior patterns of the embryo. The maternal-effect loci required for patterning in the anteroposterior axis of the embryo can be divided into three groups (for review, see Nüsslein-Volhard et al. 1987). The first group is necessary for the establishment 
of the anterior pattern of the embryo, including the acron, head, and thorax (Frohnhöfer and Nüsslein-Volhard 1986, 1987; Driever and Nüsslein-Volhard 1988a,b). The second group, known as the grandchildless-knirps (Schüpbach and Wieschaus 1986) or posterior group, is required for the pattern in the posterior half of the embryo, including posterior pole plasm and abdominal segmentation (Boswell and Mahowald 1985; Lehmann and Nüsslein-Volhard 1986, 1987; Schüpbach and Wieschaus 1986). The third group acts to specify the pattern at both ends of the embryo, namely the acron anteriorly and the telson posteriorly (Degelman et al. 1986; Schüpbach and Wieschaus 1986; Klingler et al. 1988; Strecker et al. 1989|. In the dorsoventral axis, most of the loci identified are required to establish ventral cell fates, so that 'dorsalization' occurs in loss-of-function mutations, with embryos lacking structures derived from the more ventrally specified mesoderm and neurogenic ectoderm (for review, see Anderson 1987). Because all of the reported maternal-effect loci that affect pattern formation are involved in generating either the dorsoventral or anteroposterior axis, but not both, these two axes of the embryo seem to be specified independently of one another.

A small group of loci have been identified that produce similar pattern alterations in both the eggshell and embryo, when mutated. This allows the pattern of the embryo to be related to cellular patterns and spatial organization already visible during oogenesis. This relationship is intriguing because the eggshell and embryo are made by two very different cell types. The eggshell is secreted by somatically derived follicle cells, whereas the embryo develops inside the germ-line-derived egg cytoplasm. Females mutant for $f_{s}(1) K 10$ produce almost symmetrically shaped eggs with dorsal appendage material secreted around the entire anterior end in a ring (Wieschaus et al. 1978; Wieschaus 1979, 1980; Wieschaus and Szabad 1979). During oogenesis, the developing oocyte and the surrounding follicle cells form a dorsalized egg chamber. Embryos developing inside $f_{s}(1) K 10$ eggs are dorsalized also. torpedo (top) and gurken (grk) (Schüpbach 1987) are maternal-effect loci with the opposite effects from $f_{s}(1) K 10$ on egg and embryonic patterns. Mutant mothers produce elongated eggs with little or no dorsal appendage material /corresponding to ventralization during oogenesis) and ventralized embryos. The correspondence between pattern defects of the eggs and embryos from $f_{s}(1) K 10$, top, and grk mutant mothers indicates a relationship between the genetically defined asymmetries of oogenesis and embryogenesis.

In this paper we describe two additional maternal-effect loci, cappuccino (capu) and spire (spir), that are required for patterning during both oogenesis and embryogenesis. Mutations in these loci result in the production of $f_{S}(1) K 10$-like eggs containing dorsalized embryos. A striking feature of both loci is that mutant embryos also contain very specific alterations in the anteroposterior axis. These defects closely resemble those caused by mutations in the grandchildless-knirps or posterior group of maternal-effect loci. capu and spir are therefore the first loci known to be involved in patterning in both the dorsoventral and anteroposterior axes of the embryo. Their existence indicates that the dorsoventral and anteroposterior patterning processes share some common features.

\section{Results}

Twelve alleles of spir $(2-54)$ and five alleles of capu $(2-8)$ were isolated in several screens for female sterile mutations. The alleles can be placed in a phenotypic series. Females mutant for weaker alleles produce embryos lacking pole cells, polar granules, and normal abdominal segmentation. Females mutant for stronger alleles produce dorsalized eggshells and embryos (see Table 1).

Embryos produced by capu or spir mutant females resemble those produced by the posterior or grandchildless-knirps group of maternal-effect mutants

Females mutant for capu or spir produce embryos lacking pole cells, posterior pole plasm, and normal abdominal segmentation, defects typical of the posterior or grandchildless-knirps class of maternal-effect mutants. Pole cells, the progenitor cells of the germ line (Mahowald et al. 1979), which form at the posterior pole of a normal embryo, are absent in all embryos laid by mutant females (see Fig. 1). A small fraction of the offspring of females homozygous for the weakest alleles (e.g., ca$\left.\mathrm{pu}^{\mathrm{HK}}{ }^{\mathrm{B}} \mathrm{spir}^{41}\right)$ survive to adulthood. Examination of the gonads dissected from these adults indicates that they are agametic, confirming that this aspect of the mutant phenotype is $100 \%$ penetrant.

Mutant embryos are also missing polar granules, electron-dense ribonucleoprotein structures normally found in the posterior cytoplasm of wild-type embryos, thought to be important in specification of the germ line (Mahowald et al. 1979). Electron micrographs of sections from the posterior pole of early embryos from capu $^{H K 3}{ }^{,}$spir $^{R P}$ homozygous mutant mothers failed to reveal the presence of any polar granules, although polar granules were observed in sections of wild-type embryos of the same developmental stage (see Fig. 1). In addition, mutant embryos and egg chambers do not accumulate the vasa protein, a component of the polar granules, at the posterior pole. In wild-type females, the vasa protein is seen first at the posterior pole during oogenesis in stage-10 egg chambers and becomes incorporated into the pole cells during embryogenesis (Hay et al. 1988a,b). To visualize the distribution of the vasa protein in mutant embryos, embryos derived from capu ${ }^{G 7 /}$ $D f(2 L) e d^{S Z 1,2}$ and homozygous $s{ }^{R P}{ }^{R P}$ females were immunostained with a monoclonal antibody that reacts with vasa protein $(\mathrm{mAb} 46 \mathrm{Fll}$, generously provided by Bruce Hay). Mutant embryos do not exhibit concentrated staining in the posterior pole (Fig. 1). To determine whether the vasa protein is localized initially to the posterior pole during oogenesis, ovaries from $c^{c a p u} u^{G 7} / D f(2 L) e d^{S Z 1,2}$ and spir $^{R P}$ females were sectioned 
Table 1. Percentages of eggshell and cuticle phenotypes of unhatched eggs produced by females of various mutant genotypes

\begin{tabular}{|c|c|c|c|c|c|c|c|}
\hline & \multirow{2}{*}{\multicolumn{2}{|c|}{$\begin{array}{c}\text { Eggshell } \\
\text { phenotype } \\
(\%)\end{array}$}} & \multicolumn{4}{|c|}{ Cuticle phenotype $(\%)$} & \multirow[b]{2}{*}{$\begin{array}{l}\text { Miscellaneous } \\
|\%|\end{array}$} \\
\hline & & & unfertilized & dorsa & $\mathrm{ed}^{\mathrm{a}}$ & $\begin{array}{l}\text { knirps }^{b} \\
|\%|\end{array}$ & \\
\hline \multicolumn{8}{|l|}{ capu } \\
\hline \multirow[t]{2}{*}{ HK3/HK3 } & normal & 86 & 22 & 10 & & 68 & 0 \\
\hline & abnormal & 14 & 79 & 15 & $|+57=72|$ & 6 & 0 \\
\hline \multirow[t]{2}{*}{ HK3/Df } & normal & 55 & 25 & 22 & & 53 & 0 \\
\hline & abnormal & 45 & 69 & 28 & $(+44=72)$ & 3 & 0 \\
\hline \multirow[t]{2}{*}{ RK/RK } & normal & 55 & 45 & 11 & & 45 & 0 \\
\hline & abnormal & 45 & 72 & 14 & $(+27=41)$ & 14 & 1 \\
\hline \multirow[t]{2}{*}{$\mathrm{RK} / \mathrm{Df}$} & normal & 27 & 12 & 29 & & 59 & 0 \\
\hline & abnormal & 73 & 77 & 15 & $(+65=80)$ & 8 & 0.4 \\
\hline \multirow[t]{2}{*}{$\mathrm{G} 7 / \mathrm{G} 7$} & normal & 14 & 45 & 0 & & 55 & 2 \\
\hline & abnormal & 86 & 72 & 5 & $\{+27=32\}$ & 20 & 0 \\
\hline G7/Df & normal & 30 & 38 & 16 & & 42 & 1 \\
\hline spir & abnormal & 70 & 46 & 19 & $(+8=27)$ & 31 & 4 \\
\hline \multirow[t]{2}{*}{$41 / 41$} & normal & 95 & 33 & 40 & & 27 & 0 \\
\hline & abnormal & 5 & 58 & 42 & $(+25=67)$ & 0 & 0 \\
\hline \multirow[t]{2}{*}{ 41/Df } & normal & 33 & 55 & 8 & & 33 & 1 \\
\hline & abnormal & 67 & 74 & 18 & $(+19=37)$ & 8 & 0 \\
\hline \multirow[t]{2}{*}{$03 / 03$} & normal & 66 & 41 & 18 & & 40 & 1 \\
\hline & abnormal & 34 & 67 & 20 & $(+26=46)$ & 13 & 0 \\
\hline \multirow[t]{2}{*}{ 03/Df } & normal & 32 & 37 & 9 & & 54 & 0 \\
\hline & abnormal & 68 & 69 & 15 & $(+36=51)$ & 16 & 0 \\
\hline \multirow[t]{2}{*}{$\mathrm{RP} / \mathrm{RP}$} & normal & 41 & 46 & 11 & & 42 & 1 \\
\hline & abnormal & 59 & 53 & 30 & $(+7=37)$ & 17 & 0 \\
\hline \multirow[t]{2}{*}{$\mathrm{RP} / \mathrm{Df}$} & normal & 35 & 39 & 19 & & 42 & 0 \\
\hline & abnormal & 65 & 74 & 14 & $(+35=49)$ & 12 & 0 \\
\hline
\end{tabular}

Larvae hatch from a small percentage of eggs laid by mutant females. The percentages of the total eggs laid that hatch are as follows: $\mathrm{capu}^{H K 3}, 15 \%$; capu ${ }^{R K 12}, 2 \%$; capu ${ }^{G 7}, 1 \%$; spir ${ }^{41}, 8 \%$; spir ${ }^{03}, 3 \%$; and $\operatorname{spir}^{R P}, 4 \%$.

a In the case of the strong chorion phenotype, there is often a substantial increase in the number of unfertilized eggs as compared to the normal eggs produced by the same females. When fertilized, such strongly dorsalized eggs would show the dorsalized cuticle phenotype. Therefore, the difference between the percentage of unfertilized eggs in the normal and abnormal categories should be added to the percentage of dorsalized eggs (numbers in parentheses).

b Some of these knirps-type embryos have head defects.

and stained with the antibody. We did not observe staining in the posterior pole of egg chambers from either mutant, although wild-type sections on the same slides were labeled clearly by the antibody (data not shown). This suggests vasa protein is not localized correctly at the posterior pole of mutant egg chambers during oogenesis.

Females homozygous for capu and spir produce embryos with abdominal segmentation defects similar to those produced by mutations in the grandchildlessknirps or posterior class of maternal-effect loci (Boswell and Mahowald 1985; Lehmann and Nüsslein-Volhard 1986, 1987; Schüpbach and Wieschaus 1986). These embryos have relatively normal heads and thoraces but show abdominal segmentation defects ranging from fusion of neighboring segments to deletion of all of the $a b$ dominal segments (see Fig. 2B). The severity of abdominal defects varies between different alleles. For example, in the weak allele $\mathrm{Capu}^{\mathrm{HK} 3}$, a large fraction of embryos have only minor abdominal segmentation defects, whereas in $c a p u^{R K}$, most embryos are entirely lacking abdominal segments. Moreover, when a weak or intermediate allele is tested in trans to a chromosomal deficiency, the frequency of abdominal defects increases, indicating that the severity of the defects is correlated to the amount of gene product present (see Table 1). In mutant embryos the expression pattern of fushi tarazu (ftz), a gene that normally is expressed in seven transverse stripes at the cellular blastoderm stage (Hafen et al. 1984; Carroll and Scott 1985), is similar to that produced by mutants in other members of the grandchildlessknirps group of loci (Carroll et al. 1986). To simplify the task of visualizing $\mathrm{ftz}$ expression, male carrying a $\mathrm{ftz}-$ lacZ gene fusion [kindly provided by Yash Hiromi (Hiromi et al. 1985)] were mated with $\mathrm{capu}^{R K}$ and $\mathrm{spir}^{03}$ homozygous females, and the $\beta$-galactosidase pattern in the mutant offspring was visualized using immunostaining. The ftz-lacZ pattern is abnormal in almost all $\operatorname{capu}^{R K}$ and $s p i r^{03}$ mutant embryos. In $s p i r^{03}$ most of the embryos have only four stripes, instead of the normal seven. The anterior two stripes are of relatively normal spacing, width, and intensity, followed by a broad faint third stripe and a fourth normal stripe (see Fig. 3). Some of the $c a p u^{R K}$ mutant embryos have a ftz pattern similar to spir ${ }^{03}$, although some have additional stripes in the region between the second and posterior-most stripe, similar to the weaker mutations in the posterior group genes (Carroll et al. 1986; Lehmann 1988). 


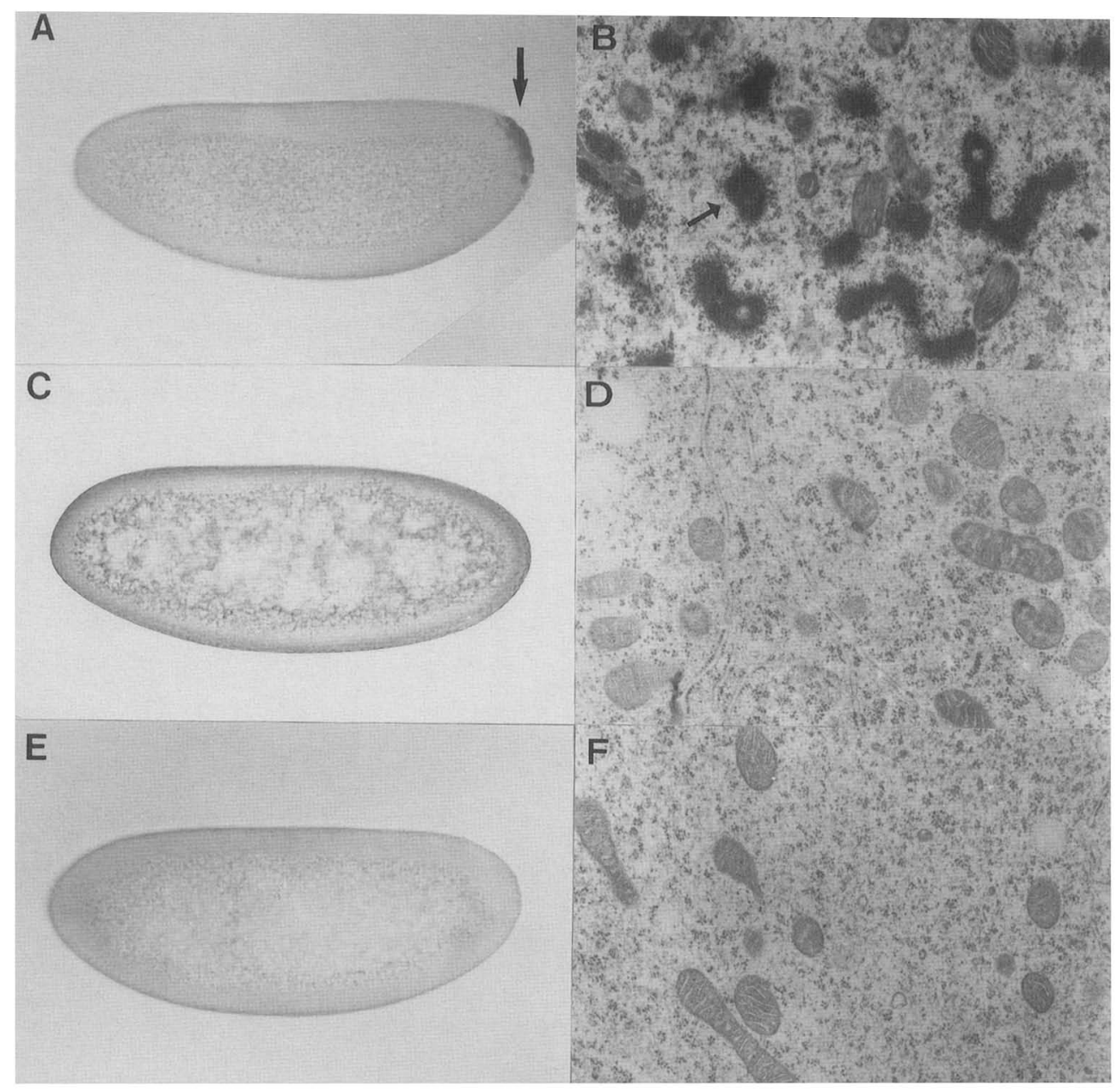

Figure 1. The grandchildless phenotype: Embryos from mutant mothers lack pole cells, polar granules, and localized vasa protein. $\{A, C$, and $E\rangle$ Embryos undergoing cellularization that have been immunostained with a monoclonal antibody that reacts with the vasa protein. Wild-type embryos $(A \mid$ have pole cells and vasa staining at the very posterior end $($ arrow $\mid$, whereas embryos from capu $|C\rangle$ and spir $(E)$ females lack pole cells and localized vasa staining. $(B, D$, and $F)$ Polar granules are present in electron micrographs of sections from the posterior end of a wild-type embryo $(B$; arrow), but absent in sections from capu $(D)$ and spir $(F)$ embryos. Genotype of mother: $(A$ and $B)$ Wild-type; $(C) c^{c a p u^{G T} / D f} ;(D) \mathrm{capu}^{H K 3} / \mathrm{capu}^{H K 3} ;(E$ and $F)$ spir $^{R P} /$ spir $^{R P}$. Anterior is to the left and dorsal is $u p$.

capu and spir mutant egg chambers contain the 'posterior activity' required for abdominal segmentation

The various members of the posterior or grandchildlessknirps group of loci show striking differences in their effects on the bicaudal pattern produced by Bicaudal $D$ (Bic-D). Bic-D is a dominant maternal-effect mutation that produces symmetrical bicaudal embryos (Mohler and Wieschaus 1985, 1986). Some members of the posterior group in combination with Bic-D suppress the formation of an anterior abdomen, whereas others do not (Lehmann 1985; Lehmann and Nüsslein-Volhard 1986; R. Lehmann, pers. comm.). Therefore, we examined the phenotype of embryos produced by females homozygous for $c a p u^{R K}$ or $s p i r^{R P}$ and heterozygous for Bic- $D^{71.34}$. A number of different types of embryos are produced, in keeping with the variability of capu, spir, and Bic-D. In phenotypically bicaudal embryos, the posterior half of the embryo (i.e., that with normal polarity) shows reduction in segemental pattern typical of capu or spir, whereas the anterior half (i.e., that with reverse polarity) shows normal segmentation (see Fig. 4). This indicates that mutations in capu and spir do not absolutely prevent the formation of abdominal segments but specifically interfere with abdominal segmentation in the posterior half of the embryo.

Some embryos produced by capu or spir mutant females resemble those produced by the dorsalizing class of maternal-effect mutants

Females homozygous or hemizygous for the stronger alleles of capu and spir produce dorsalized embryos (Table 1). The dorsalized phenotype can be seen in the cuticle at the end of embryogenesis (see Fig. 2C). The cuticle is a twisted tube with no denticle bands present on the ventral surface. The first evidence of the dorsalized embry- 


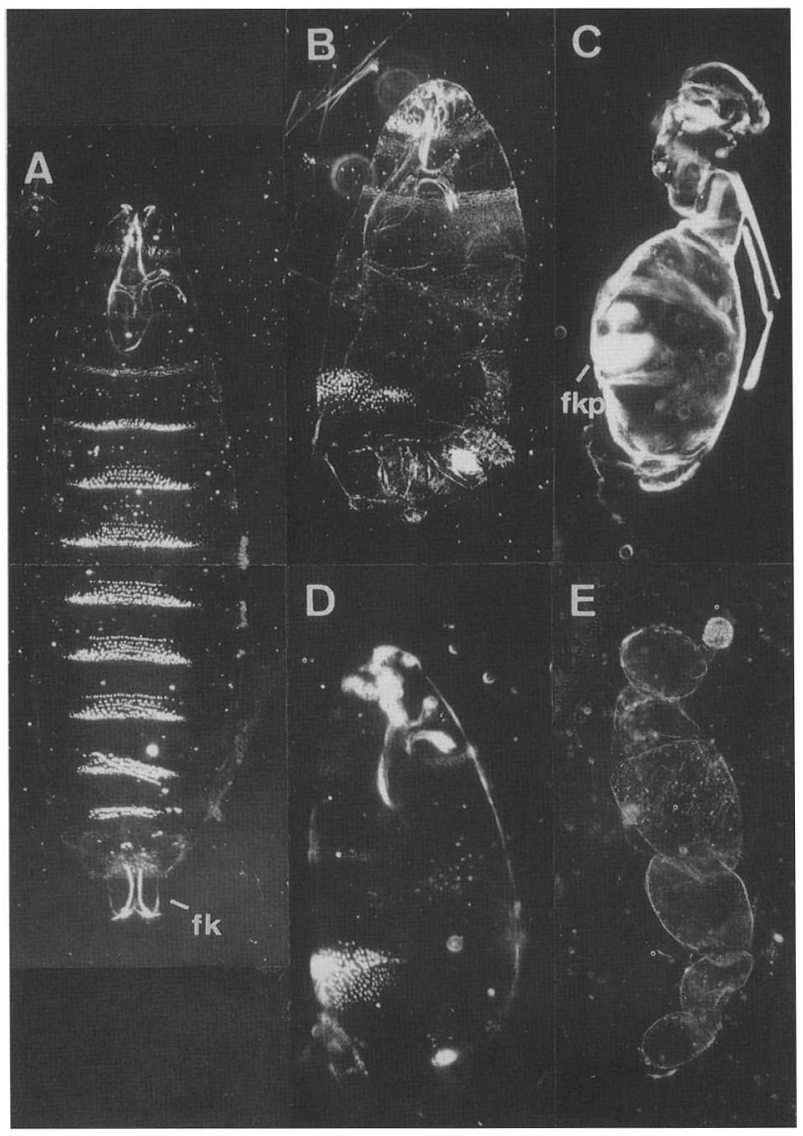

Figure 2. Embryos from mutant mothers produce cuticle resembling that of the grandchildless-knirps or dorsalizing classes of maternal-effect loci. $(A \mid$ Wild-type cuticle; $\mid B$ and $D \mid$ grandchildless-knirps-type cuticles typical of spir or capu $|B|$ and from tudor $(D)$, a member of the grandchildless-knirps group of loci (Boswell and Mahowald 1985; Schüpbach and Wieschaus 1986); $(C$ and $E$ ) dorsalized cuticles typical of capu or spir $(C)$ and from dorsal $(E)$. Genotypes of mothers: $(B)$ spir $^{03}$; (C) $\operatorname{capu}^{R K} ;(D)$ tud ${ }^{w C 8},(E) \operatorname{In}(2 L) d l^{H} / D f(2 l) T W 119$. (fk) Filzkörper; (fkp) filzkörper patch.

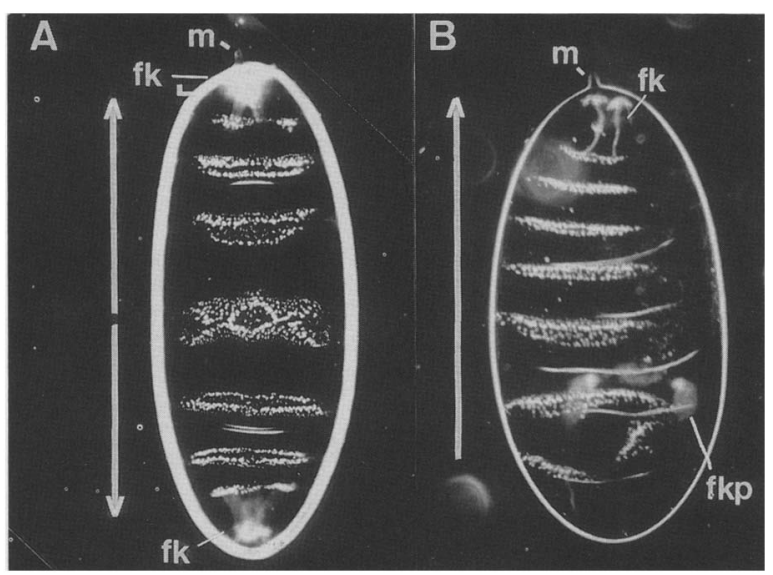

Figure 4. Femaies doubly mutant for Bic-D and capu or spir are able to produce embryos with normal abdominal segmentation in the anterior of a bicaudal embryo, indicating that capu and spir embryos possess the posterior determinant. $(A)$ Cuticle of a symmetrical bicaudal embryo. $(B)$ Cuticle of a bicaudal embryo from a $\operatorname{spir}^{03}$ Bic- $D^{71.34} /$ spir $^{R P}$ female. This embryo exhibits normal abdominal segmentation with reversed polarity) in the anterior of the egg [marked by the micropyle $(\mathrm{m})]$ but shows the abdominal segment deletions and filzkörper patches (fkp) (in an underlying focal plane), typical of spir in the posterior of the egg. (fk) Filzkörper. Large arrows indicate the polarity of the segments from anterior to posterior.

onic phenotype can be seen during gastrulation (e.g., Figs. 3 and 5). In many of the embryos derived from females homozygous for the strongest alleles, the ventral furrow is reduced or absent. Abnormal folds appear on the dorsal and ventral surfaces as the germ band fails to extend dorsally. In fixed embryos, it is possible to see that the cephalic furrow is more perpendicular to the longitudinal axis of the embryo than in wild type. These gastrula resemble those produced by other members of the dorsalizing class of maternal-effect loci, although capu and spir dorsalized gastrula have a reduced number of folds in the abdominal region.

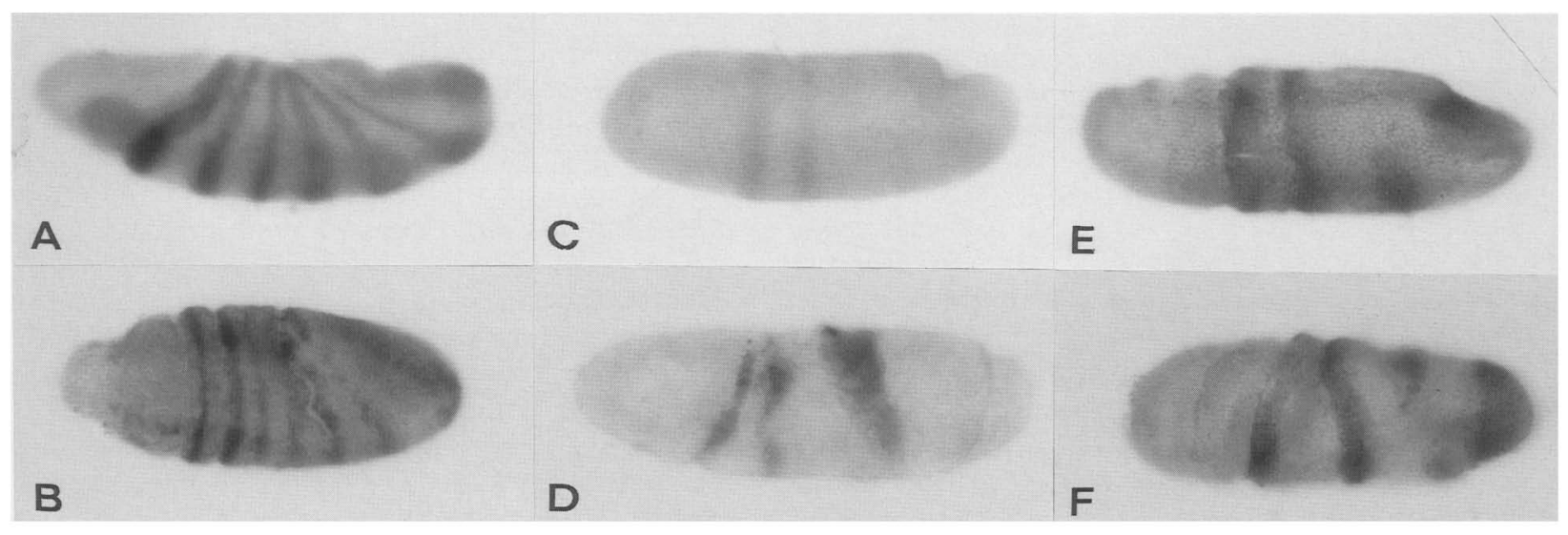

Figure 3. Embryos from capu and spir mutant mothers exhibit altered $f t z$ expression, similar to that observed in the grandchildless knirps class of loci. Wild-type $(A)$ embryos have seven stripes of $f t z$ expression, as do dorsalized embryos produced by members of the dorsal group of maternal-effect loci (Carroll et al. 1987) and $f_{S}(1) K 10(B)$ capu $^{R K}$ females $(C$ and $D)$ and $\operatorname{spir}^{03}(E$ and $F)$ females produce embryos with a reduced number of $f t z$ stripes. Typically, the anterior two stripes are normal. More posterior is a broad, sometimes faint, stripe and a posterior stripe of normal width. Embryos in $C, E$, and $F$ are dorsalized to various extents. 


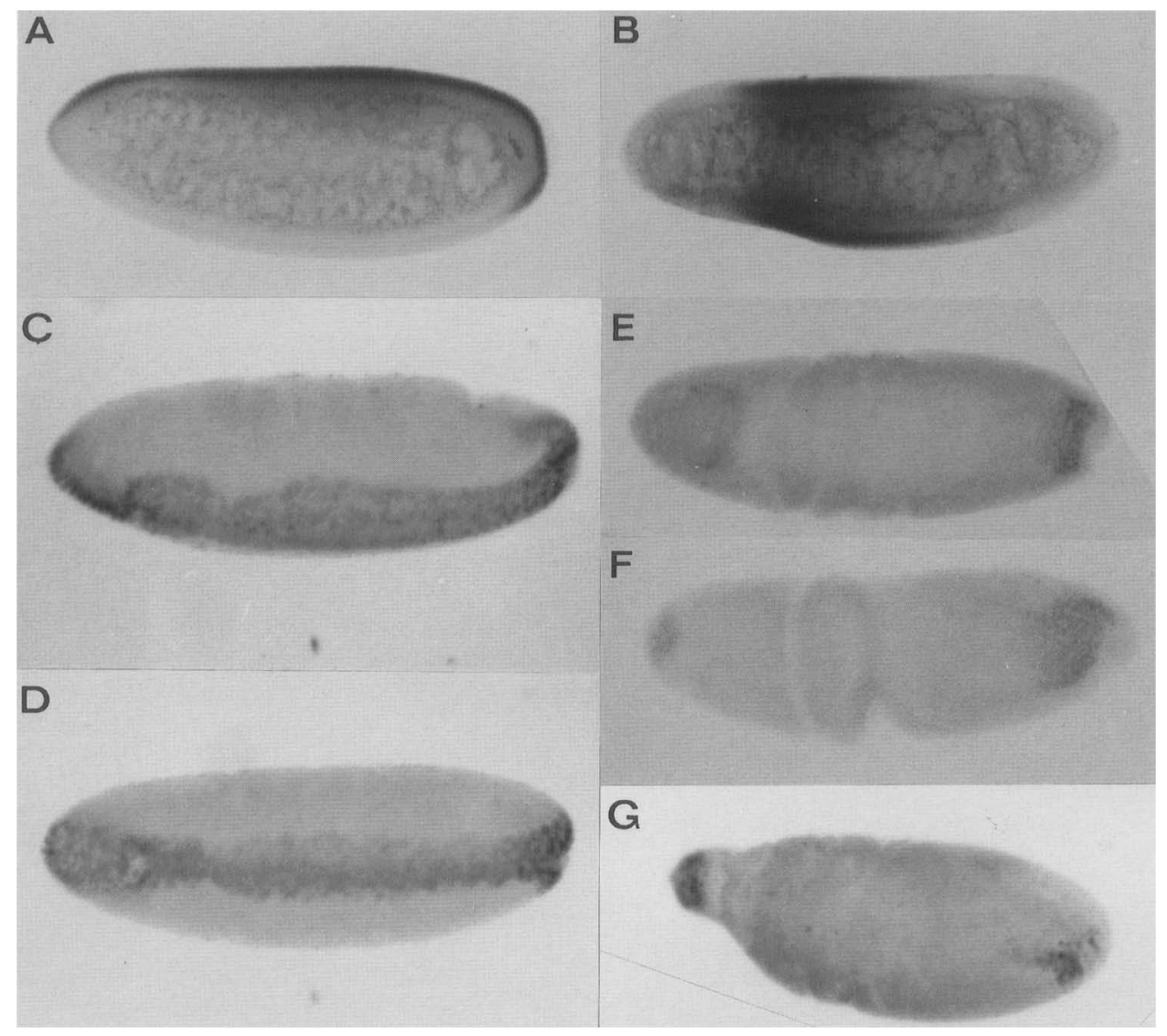

Figure 5. Immunostaining with antibodies against zen and twist protein indicates that some embryos from mutant mothers are dorsalized. $(A$ and $B)$ Embryos stained with an antibody directed against zen protein. $(A)$ Wild type express zen dorsally. (B) An embryo from $\mathrm{capu}^{R K}$ that exhibits expansion of zen staining around the ventral circumference as is seen in the dorsalizing class of loci (Rushlow et al. 1987). Similar expansions of zen staining are observed in spir mutant embryos. $(C-G)$ Embryos stained with an antibody directed against twist protein. $(C$ and $D)$ Wild type showing twist staining in a ventral strip of cells; $(E-G)$ Dorsalized embryos from $c a p u^{G 7} / D f(E$ and $F)$ and $\operatorname{spir}^{R P}(G)$. Note the absence of staining in the central regions of these mutant embryos.

To visualize the extent of dorsalization, embryos derived from capu and spir mothers were stained with antibodies to the zerknullt (zen) [generously provided by Chris Rushlow (Rushlow et al. 1987)] and twist [generously provided by Siegfried Roth (Thisse et al. 1988)] gene products. In wild-type embryos, zen protein is found first in embryos undergoing the thirteenth nuclear division in nuclei positioned at the surface of the most dorsal $40 \%$ of the embryo and at the anterior and posterior poles of the embryo. As development proceeds, zen protein becomes restricted to the dorsal side so that it is restricted to a dorsal strip 5-6 cells wide by gastrulation (Rushlow et al. 1987). Some capu and spir embryos show an expansion of zen ventrally (see Fig. 5), similar to the zen expression pattern in other dorsalizing mutants (Rushlow et al. 1987). However, in contrast to the other dorsalizing mutants, zen staining is not expanded uniformly along the anteroposterior axis but shows greater expansion of staining anteriorly than posteriorly, indicating a stronger dorsalization of more anterior regions of the embryo. In older capu and spir dorsalized embryos, the zen staining is much fainter than in wild-type controls. In wild-type embryos, twist protein is found immediately prior to gastrulation in a midventral strip of cells $\sim 12$ cells wide (Thisse et al. 1988). During gastrulation, these cells invaginate to form the ventral furrow. In some capu and spir mutant embryos, twist staining is present only in ventral cells at the anterior and posterior poles of the embryo; ventral cells in the more central regions of the anteroposterior axis do not stain (see Fig. 5). Embryos that do stain with the twist antibody in the ventral furrow region often show a band of staining that varies in width along the anteroposterior axis.

The dorsalized capu and spir embryos also exhibit grandchildless-knirps-type pattern defects. All embryos derived from mutant mothers, including the dorsalized capu and spir embryos, lack pole cells. This lack of pole cells is atypical of mutations in the dorsalizing class of loci (Nüsslein-Volhard 1979) but is characteristic of the grandchildless-knirps class of loci (Boswell and Mahowald 1985; Lehmann and Nüsslein-Volhard 1986, 1987; Schüpbach and Wieschaus 1986). In embryos with a dorsalized cuticle phenotype, it is difficult to observe the anteroposterior pattern because the ventral denticles that mark the segment pattern are missing. To visualize 
the anteroposterior pattern in embryos with a dorsalized phenotype, the expression of pattern of $f t z$ was analyzed in the mutant embryos, as described earlier. In embryos that were classified as being dorsalized on the basis of their pattern of transverse folds at gastrulation, the number of $f t z-l a c Z$ stripes is reduced /see Fig. 3C, E, and F). This is not typical of dorsalized embryos produced by the dorsal group of maternal-effect loci (Caroll et al. 1987; this study Fig. 3B, $\left.f_{s}(1) K 10\right)$ and confirms that even dorsalized capu and spir embryos have abdominal segment deletions.

\section{capu and spir participate in dorsoventral patterning during oogenesis}

Females homozygous for the strongest alleles of capu or spir produce egg chambers and eggs that appear to be dorsalized. The functional unit of oogenesis is the egg chamber, a cellular complex that consists of the developing oocyte and 15 nurse cells surrounded by a monolayer of follicle cells, which secrete the eggshell. In wild-type egg chambers at stage 11 , the follicle cells that are in contact with the dorsal, anterior side of the oocyte are distinguished easily from those on the ventral side because the dorsal follicle cells are more columnar than those on the ventral side (King 1970). In contrast, egg chambers produced by mutant females are symmetric; both the dorsal and ventral sides of the anterior oocyte are surrounded by columnar follicle cells, indicating that the egg chamber is dorsalized (see Fig. 6).

The dorsalization of the egg chamber during oogenesis is reflected in the eggshell of capu and spir mutant eggs.
Eggs from females homozygous for the strongest alleles frequently are dorsalized (see Table 1). Whereas two distinct dorsal appendages are formed at an anterodorsal location in wild type, the dorsal appendages often are fused dorsally and/or extended ventrally around the anterior circumference in the mutant (see Fig. 7). In addition, the shapes of the follicle cell imprints in the main body of the eggshell, which are elongated on the dorsal side and regularly shaped on the ventral side in wildtype eggs, do not show a dorsoventral difference in mutant eggs. The number of follicle cell imprints on the main body of the chorion is rather constant in normal eggs. In the dorsalized eggshells, the number of follicle cell imprints in the main body of the egg is reduced. Within the area of the eggshell that was analyzed (see Materials and methods|, $378 \pm 24$ follicle cells secrete main body chorion in wild type, whereas in the severely dorsalized eggs, $\sim 280$ (capu, $288 \pm 21$; spir, $276 \pm 33$ ) follicle cells are secreting main body chorion (see Table 2 ). Because the number of follicle cells secreting the main body of the eggshell is reduced, we believe that the extra appendage material present ventrally in capu and spir mutant eggs probably results from a change in cell fate, so that follicle cells normally secreting main body chorion are secreting dorsal appendage material instead. A similar reduction in the number of follicle cell imprints in the main body of the eggshell is seen for fs(1)K10 [Wieschaus 1979; this study (see Table 2)]. The most severe capu and spir chorion phenotype therefore is similar to that seen in $f s(1) K 10$, a maternal-effect mutation that produces a dorsalized chorion and embryo (Wieschaus et al. 1978; Wieschaus 1979, 1980; Wies-

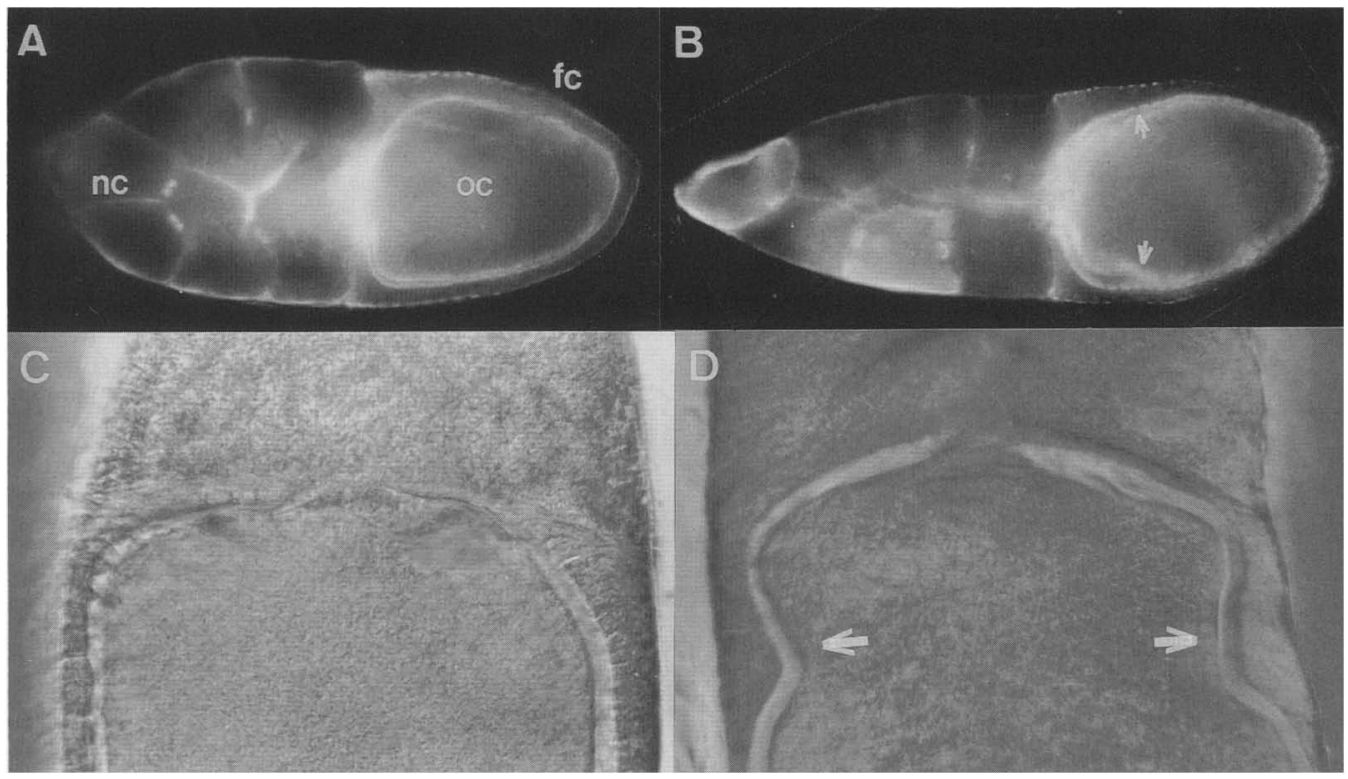

Figure 6. Mutant females contain dorsalized egg chambers. $\mid A$ and $B \mid$ Late-stage egg chambers stained with rhodamine-conjugated phalloidin. Anterior is to the left and dorsal is up. $(C$ and $D)$ Egg chambers viewed with differential interference contrast (DIC) microscopy. Anterior is up and dorsal is to the right. Wild-type egg chambers $(A$ and $C)$ exhibit a dorsoventral asymmetry in the shape and position of the follicle cells at the anterior of the oocyte. Follicle cells on the dorsal side are more columnar in this region than those on the ventral side, resulting in greater distance on the dorsal side between the surface of the egg chamber and the oocyte. In some mutant egg chambers $\left[\mathrm{capu}^{R K},(B) \mathrm{capu}^{G 7} / D f,(D)\right]$, this asymmetry is lost; the distance between the surface of the egg chamber and the oocyte is similar on the dorsal and ventral sides (see arrows). (oc) Oocyte; (fc) follicle cells; (nc) nurse cells. 


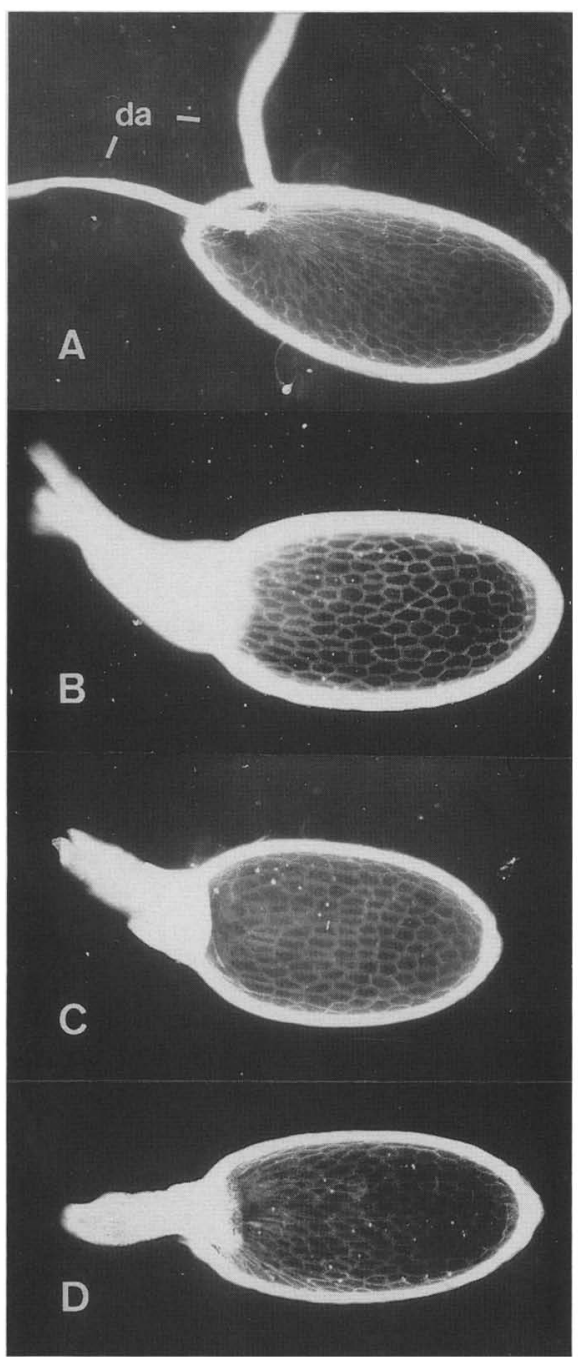

Figure 7. Mutant females produce eggshells that are dorsalized. In wild-type eggshells, two respiratory appendages extend from the dorsal anterior surface [dorsal appendages (da)]. The follicle cell imprints on the surface of the egg are more elongate on the dorsal side and more regular on the ventral surface. Strongly dorsalized eggs $(B$ and $C)$ have respiratory appendage material secreted around the entire anterior circumference of the egg in a ring and do not exhibit the normal dorsoventral asymmetry in follicle imprint shape. Some mutant eggs have respiratory appendage material in a fused appendage across the dorsal midline $(D)$. Genotypes of the mothers: $f_{S}(1) K 10(B)$; $\operatorname{spir}^{03}(C$ and $D)$.

chaus and Szabad 1979). As the dorsal appendage material is also secreted over the dorsal midline in some capu and spir eggs, the egg phenotype sometimes differs from that of $f_{S}(1) K 10$.

The chorion and embryonic phenotypes of capu and spir are roughly correlated - an egg with more wild-type chorion phenotype usually contains an embryo with weaker abdominal segmentation defects; an egg with the extreme chorion phenotype, if fertilized, usually contains an embryo that has extreme abdominal segmentation defects and is dorsalized (see Table 1).
Table 2. Number of follicle cell imprints counted per egg

\begin{tabular}{|c|c|c|c|c|c|}
\hline \multirow{2}{*}{$\frac{\text { Wild type }}{372}$} & \multicolumn{2}{|c|}{ сарu } & \multicolumn{2}{|c|}{ spir } & \multirow{2}{*}{$\frac{f_{s}(1) K 10}{312}$} \\
\hline & RK/Df & 265 & $\mathrm{PJ} / \mathrm{PJ}$ & 231 & \\
\hline 413 & RK/RK & 292 & $03 / 03$ & 297 & 296 \\
\hline 368 & & 323 & & 313 & 267 \\
\hline 349 & & 289 & & 286 & 267 \\
\hline 388 & & 268 & & 253 & 291 \\
\hline Mean 37 & \pm 24 & $288 \pm 21$ & & $276 \pm 33$ & $287 \pm 20$ \\
\hline
\end{tabular}

Follicle cell imprints were counted on two surfaces for every egg, but because of the curvature of the egg, not all follicle cells were counted.

capu and spir are required in germ-line-derived cells during oogenesis

To determine whether capu and spir function in the oocyte-nurse cell complex, genetically mosaic egg chambers were studied. Mosaics in which the oocyte and nurse cells were mutant, but were surrounded by wild-type follicle cells, were constructed by two methods. In the first method, pole cells from homozygous $\mathrm{capu}^{R K}$ or $\mathrm{spir}^{03}$ embryos were transplanted into embryos carrying ${ }^{2} O^{D 1}$ (see Table 3), a dominant germline-dependent female sterile mutation that prevents development of the female germ line (Busson et al. 1983; Perrimon and Gans 1983). In such host females, only the transplanted pole cells can produce eggs. In the second method, germ-line mosaics were induced by irradiation of larvae transheterozygous for $F s(2) 1$ (Macdonald and Struhl 1986; Szabad et al. 1987) and either $c a p u^{R K}$ or spir $^{P I}$ according to the dominant female sterile technique (Wieschaus 1980).

For both capu and spir, the eggs that developed from the mosaic egg chambers exhibited all aspects of the mutant phenotype (data not shown). Examination of live pregastrulation embryos from the mosaic females indicated that the embryos lacked pole cells. Cuticle preparations of unhatched eggs revealed that both dorsalized embryos and embryos with abdominal segmentation defects were produced. In addition, some of the eggs had chorions with fused dorsal appendages. These results indicate that capu and spir are required in the germ-linederived oocyte-nurse cell complex. However, the frequency of the more severe phenotypes-dorsalized chorion and embryo-was reduced, which potentially may indicate that the somatic surrounding can modify the expression of the mutant phenotype.

\section{capu and spir embryos exhibit defects during cellularization}

capu and spir mutant females produce a large fraction of embryos that cellularize incorrectly. Many of the blastoderm-stage embryos have patches of cells of different size and density (see Fig. 8). A large percentage of the embryos from females mutant for strong or weak alleles exhibit this aspect of the mutant phenotype $\left(s p i i^{41}, 57 \%\right.$; spir $^{R P}, 71 \%$; capu ${ }^{H K 3}, 50 \%$; capu $\left.{ }^{G 7} / D f, 57 \%\right)$. Examination of embryos undergoing cellularization stained with 
Table 3. Germ-line mosaics for capu and spir

\begin{tabular}{|c|c|c|c|c|}
\hline $\begin{array}{l}\text { Donor } \\
\text { parents }^{a}\end{array}$ & $\begin{array}{l}\text { No. of injected } \& \text { that } \\
\text { survive to adulthood }\end{array}$ & No. of mosaic $?$ & $\begin{array}{l}\text { No. of mosaic } q \text { that } \\
\text { produce phenotypically } \\
\text { wild-type eggs and embryos }\end{array}$ & $\begin{array}{l}\text { No. of mosaic } q \text { that } \\
\text { produce mutant eggs } \\
\text { and embryos }\end{array}$ \\
\hline capu/CyO $q \times$ capu/capu $\delta$ & 24 & 6 & 3 (capu/CyO) & 3 (capu/capu) \\
\hline spir/CyO $q \times$ spir/spir o & 25 & 5 & 2 (spir/CyO $)$ & 3 (spir/spir $\}$ \\
\hline
\end{tabular}

a Only genotypes with respect to spir or capu are given. For exact donor genotypes, host genotypes, and test partners, see Materials and methods. Note that the offspring of homozygous females lack pole cells, not the homozygous flies, themselves.

the nucleic acid stain fuchsin (Zalokar and Erk 1976; Wieschaus and Nüsslein-Volhard 1986) indicated that embryos produced by capu and spir females contain patches of relatively smaller cells that are of a density similar to wild type and patches of larger cells that are less dense than in wild type (see Fig. 8D, E, G, and H). In addition, spir mutant females produce embryos in which the larger cells are of a density similar to wild type and the smaller cells are more dense than in wild type (see Table 4). During the early cleavage divisions, embryos containing abnormal numbers of nuclei can be found. In eggs laid by spir $^{R P}$ females, we observed 13 with the normal number of nuclei (i.e., $2^{n}$ ), but 5 with abnormal numbers $(5,5,14,14,23)$. From $\mathrm{Capu}^{G 7} / \mathrm{Df}$ females, 12 embryos with the normal number of nuclei were counted and 2 with abnormal numbers $(24,26)$. In addition, the nuclei often fail to migrate properly along the anteroposterior axis, leading to abnormal distributions of nuclei when they arrive at the periphery. Time-lapse video films of embryos from $c a p u^{R K}$ and $\operatorname{spir}^{R P}$ mutant females indicate that the stages of nuclear division immediately preceding cellularization often are asynchronous.

\section{Epistatic relationships of the loci that influence patterning of the egg and embryo}

Because mutations in capu and spir cause absence of pole cells, loss of abdominal segmentation, and variable dorsalization of eggshell and embryo, it seemed possible that the capu,spir double-mutant phenotype would be more extreme and cause all eggs and embryos to be dorsalized. The phenotype of offspring from females homozygous for the strong alleles $c a p u^{R K},{ }_{\text {, }}{ }^{2} r^{03}$ is, however, similar to that of either mutant by itself /data not shown). In particular, the frequency of the dorsalized phenotype does not increase significantly in the double mutant.

To establish the epistatic relationship between capu and spir and the other genes that affect patterning of the eggshell and embryo, eggs laid by females doubly mutant for all of the pairwise combinations of capu or spir with $f_{s}(1) K 10, g r k$, and top were examined. $f_{s}(1) K 10$ is a recessive female sterile locus in which both the eggshell and embryo are dorsalized (Wieschaus et al. 1978; Wieschaus 1979, 1980; Wieschaus and Szabad 1979). Both $f_{s}(1) K 10 ;$ spir $^{03}$ and $f_{S}(1) K 10 ;$ capu $^{R K}$ double-mutant females produce eggs with strongly dorsalized chorions, similar to those produced by $f_{s}(1) K 10$ females. Eggs from $f_{s}(1) K 10$; spir ${ }^{03}$ are not fertilized, presumably because the strong dorsalization of the chorion prevents sperm entry (through the micropyle). Approximately 1\% of the eggs produced by $f_{s}(1) K 10$ females are fertilized, suggesting that the chorion phenotype of eggs from $\mathrm{fs}_{\mathrm{s}}(1) \mathrm{K} 10$; spir $\mathrm{O}^{3}$ females is somewhat enhanced. The embryos produced by $f_{S}(1) K 10_{;} c_{a p u^{R K}}$ females always are dorsalized also. Observation of pregastrulation embryos indicates that they lack pole cells. grk and top are recessive female sterile loci that produce ventralized eggs and embryos (Schüpbach 1987). These eggs are elongated, with fused and reduced dorsal appendages. The embryonic cuticle consists only of a patch of ventral cuticle. In $c a p u^{R K}$ $g_{r} k^{W G}$, in $g r k^{W G}$ spir $^{R P}$, in $c a p u^{R K}$ top $^{1}$, and in $\operatorname{spir}^{R K}$ top ${ }^{1}$, both the egg and embryo are ventralized, indicating that the ventralizing loci grk and top are epistatic to the dorsalizing action of capu and spir in the dorsoventral axis. The ventralized embryos from the double-mutant females also have abdominal segmentation defects and lack pole cells, indicating that the abdominal segmentation defects of capu and spir are additive to and independent of the dorsoventral defects.

\section{Discussion}

Females homozygous for capu and spir produce eggs and embryos with very specific pattern defects. All of the embryos lack pole cells and most have abdominal segmentation defects. These defects in the anteroposterior embryonic pattern are similar to those produced by the grandchildless-knirps group of maternal-effect loci. Some alleles also produce eggs and embryos that are dorsalized, similar to those produced by the dorsalizing group of maternal-effect loci and $f_{S}(1) K 10$.

The different pattern phenotypes observed correlate with the amount of gene activity. Females homozygous for certain alleles produce mostly embryos with pole cell and segmentation defects. These alleles are presumably homomorphic, because the phenotype is more severe when the allele is transheterozygous with a deficiency for the locus. Although we are uncertain whether any of the alleles represent complete loss of gene function, those alleles that produce a high frequency of severe phenotypes, such as eggs and embryos that are dorsalized, are probably closer to amorphic, because the phenotype produced is not altered significantly when transheterozygous with a deficiency for the locus. Therefore, the allelic series indicates that pole cell formation has the highest requirement for functional gene product, with abdominal segmentation and dorsalization requiring progressively less. 


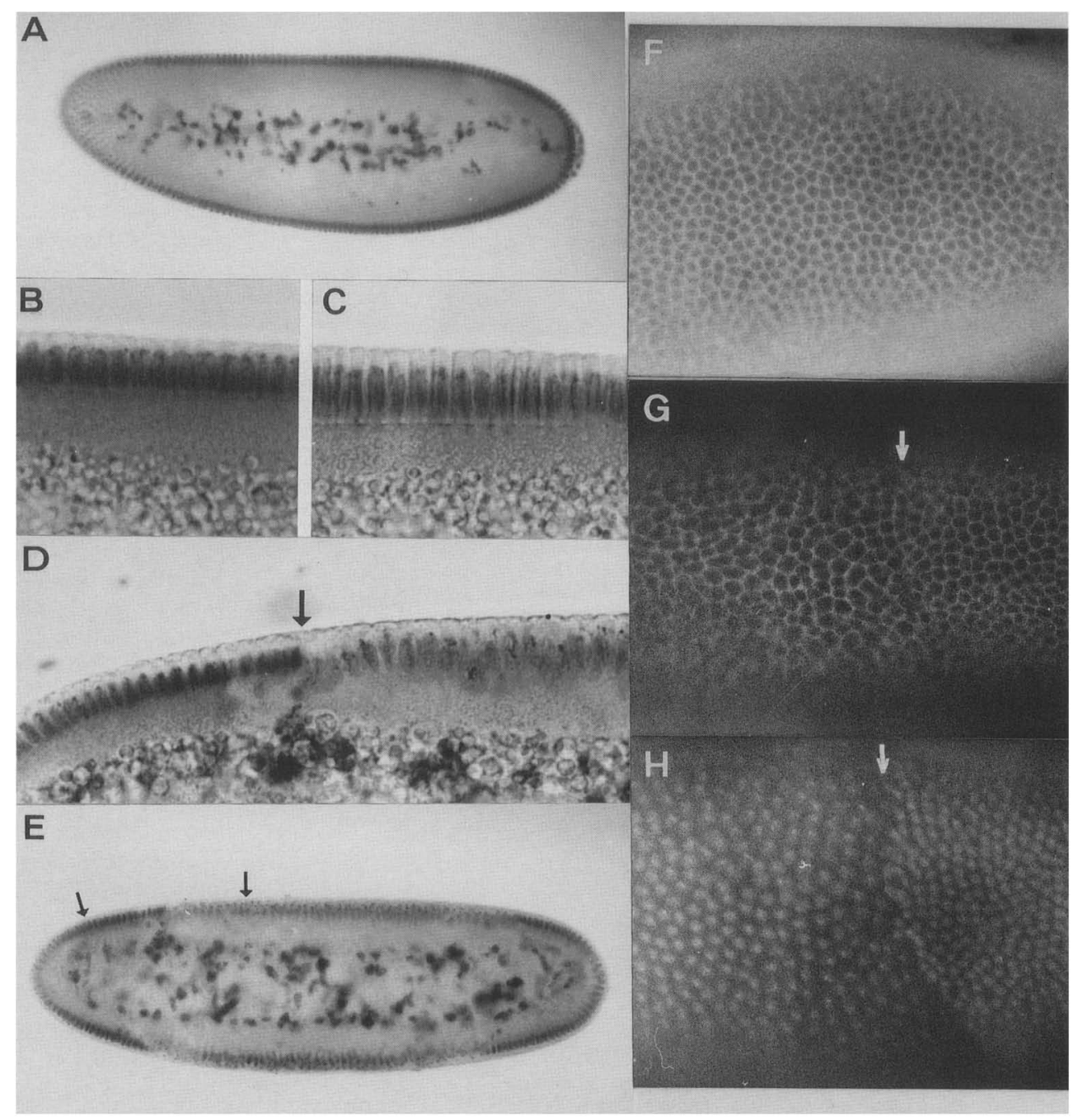

Figure 8. Embryos from mutant females exhibit abnormal nuclear densities and asynchronous cellularization during the syncytial blastoderm stage. $(A-E)$ Embryos stained with fuchsin. $(A-C)$ Wild type. $B$ and $C$ show progressive stages of cellularization in different wild-type embryos. $(D$ and $E)$ An embryo exhibiting two different stages of cellularization. The higher magnification view in $D$ was taken from the region between the two arrows in $E$. The region to the left of the arrow in $D$ is more similar in stage to the wild type shown in $B$, whereas the region to the right of the arrow in $D$ is more similar in stage to the wild type shown in $C$. The region shown to the right of the arrow in $D$ is similar in nuclear density to wild type. $(F$ and $G)$ Surface views of wild-type $(F)$ and mutant $\mid G)$ embryos stained with rhodamine-conjugated phalloidin to visualize the cell membranes. $(H)$ Hoechst staining of the same region of the mutant embryo shown in $G$. Cells and nuclei to the right of the arrow in $G$ and $H$ are more comparable in size and density to wild type. Those cells and nuclei to the left of the arrow are less dense and larger than wild type. Genotypes of mothers: $s p i r^{R P}(D$ and $E)$; spir ${ }^{R P} / D f(G$ and $H)$.

Within an individual egg, the chorion and embryonic phenotypes are roughly correlated - an egg with a more wild-type chorion phenotype usually contains an embryo with weaker segmentation defects, and an egg with the extreme dorsalized chorion phenotype, if fertilized, usually contains an embryo that has extreme abdominal segment deletions and is also dorsalized. Because this correlation is not absolute, the embryonic pattern probably does not result directly from the chorion pattern or from the pattern of follicle cells during oogenesis. Rather, both the embryonic and the follicle cell patterns reflect the results of a signaling process between the soma and the germ line (see below). Although both pat- terns probably result from the same signaling events, the final patterns are many steps removed from the actual signaling process, allowing for differences within an individual egg in the final phenotypes.

Given that there are several mutations that affect the dorsoventral patterning of oogenesis and embryogenesis simultaneously, it seems that dorsoventral patterning of the eggshell and embryo are linked. Mutations in grk and top (Schüpbach 1987) cause ventralization during oogenesis and embryogenesis, whereas mutations in capu, spir, and $f_{s}(1) K 10$ cause dorsalization of both processes. At present, it is unknown whether a direct link exists between the anteroposterior pattern of the egg- 
Table 4. Nuclear density in cellularizing embryos

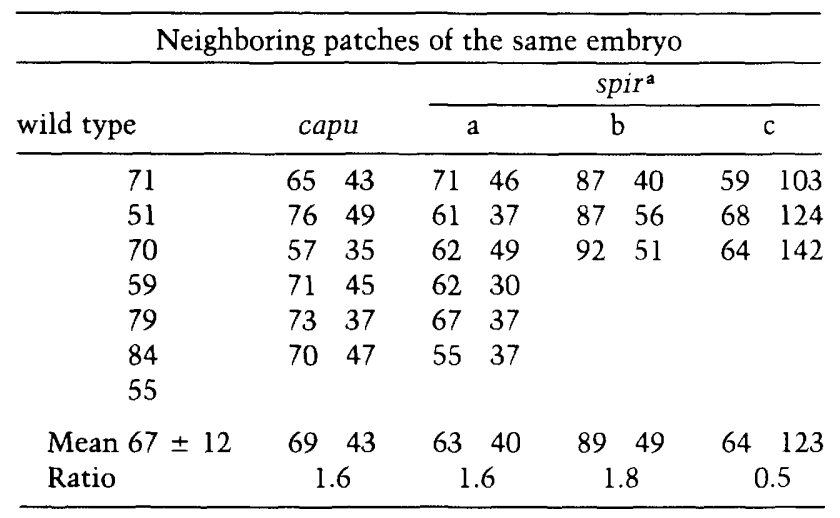

Genotypes used were capuG7/Df and spir $^{R P} /$ spir $^{R P}$. Density is given as number of nuclei per $1338.5 \mathrm{~mm}^{2}$.

a spir embryos are divided into categories: (a) those that have regions less dense; (b) of intermediate density; and (c) more dense than wild type.

shell and embryo. There are no good markers for the spatial pattern of the main body of the eggshell that would allow the detection of such a link. However, the posterior pole of the eggshell is marked by a specialized structure called the aeropyle. Although the posterior pole of the oocyte is defective in capu and spir, the aeropyle is present on the eggshells.

The relationship between the cellularization defects and the anteroposterior and dorsoventral pattern alterations in capu and spir mutant embryos is not clear. The grandchildless phenotype is apparent in the defective polar plasm of the mutant embryos before any observable nuclear density defects. This argues that the grandchildless phenotype does not result from these defects. In addition, Sullivan (1987) demonstrated that anteroposterior patterning, as visualized by $\mathrm{ftz}$ expression, occurred independent of cellular density. This indicates that the abdominal segment deletions seen in capu and spir embryos do not result from abnormal cell densities. In the dorsoventral axis, the alterations in the expression of both zen and twist are similar to those produced by the other dorsalizing mutations. It is therefore possible that capu and spir alter the function of one of the dorsal group genes and that the cellularization defects and dorsalization are also independent of one another. Defects similar to those seen in capu and spir in the density of nuclei and cells at the time of cellularization were observed in gynandromorphs by Zussman and Wieschaus (1987). These gynandromorphs survive to adulthood, without the pattern alterations seen in capu and spir, providing an additional argument that having different cell densities at the cellular blastoderm stage is not sufficient to cause the pattern alterations present in capu and spir embryos. It is interesting to note that $\mathrm{Za}$ lokar and Erk (1976) produced embryos with similar nuclear migration and cellularization defects by treatment with cytochalasin $\mathrm{B}$, a drug that inhibits polymerization of actin. This suggests that capu and spir might be affecting an actin-based transport system in the early embryo. capu and spir function in signaling processes in the germ line

Germ-line mosaics of capu and spir, made either by pole cell transplantation or mitotic recombination in the germ line, indicate that capu and spir are required in the nurse cell-oocyte complex. Because mutations in capu or spir in the germ-line-derived nurse cell-oocyte complex cause an abnormal behavior of the somatically derived follicle cells, lack of capu or spir activity must be somehow disrupting the signaling events between the oocyte and follicle cells that are required for the normal dorsoventral pattern of the egg chamber and embryo. Similar results have been obtained for $f_{s}(1) K 10$ (Wieschaus et al. 1978) and grk (Schüpbach 1987). Whether these gene products function directly in the intercellular communication process or are involved in establishing the underlying pattern of the oocyte (which is then conveyed to the follicle cells) is uncertain. However, because capu and spir seem to be required for a number of patterns in the oocyte, we think it more likely that they are required for establishing or maintaining the dorsoventral pattern of the germ cell and are not directly involved in the production of the intercellular signal.

top, on the other hand, is a gene that functions in the somatically derived follicle cells. top also is involved in a signaling process because follicle cells that are mutant for top results in ventralization of the embryo (Schüpbach 1987). The recent finding that top encodes the Drosophila homolog of the epidermal growth factor (EGF) receptor suggests that top might play a more direct role in the intercellular signaling process (Price et al. 1989; Schejter and Shilo 1989).

The epistatic relationships between the genes involved in the signaling process suggested an ordering of the genes in the early steps in dorsoventral patterning (see Fig. 9). We placed the ventralizing loci grk and top downstream of the dorsalizing loci capu, spir, and $f_{s}(1) K 10$, because the ventralizing loci are epistatic to the dorsalizing loci. Because the dorsalizing action of mutations in capu, spir, and $f_{s}(1) \mathrm{K} 10$ can be observed only in the presence of the normal grk and top gene products, we believe that $g r k$ and top mediate the effects of capu, spir, and $f s(1) K 10$. For instance, grk and top could be producing an intercellular signal in response to the underlying asymmetries produced by genes like capu, spir, and $f_{s}(1) K 10$. In the absence of grk and top gene function, then, the effects of capu, spir, and $f_{S}(1) K 10$ would be lost.

\section{Possible roles for capu and spir}

capu and spir mutations disrupt formation or stability of polar granules. This suggests that the mutant egg chambers are defective in the production of components of the polar granules, in localization of the components to the posterior end of the egg chamber, in stability of the polar granules, or in organization of the posterior cytoplasm in general.

The double mutants of Bic-D with capu and spir indicate that capu and spir are not required for abdominal 


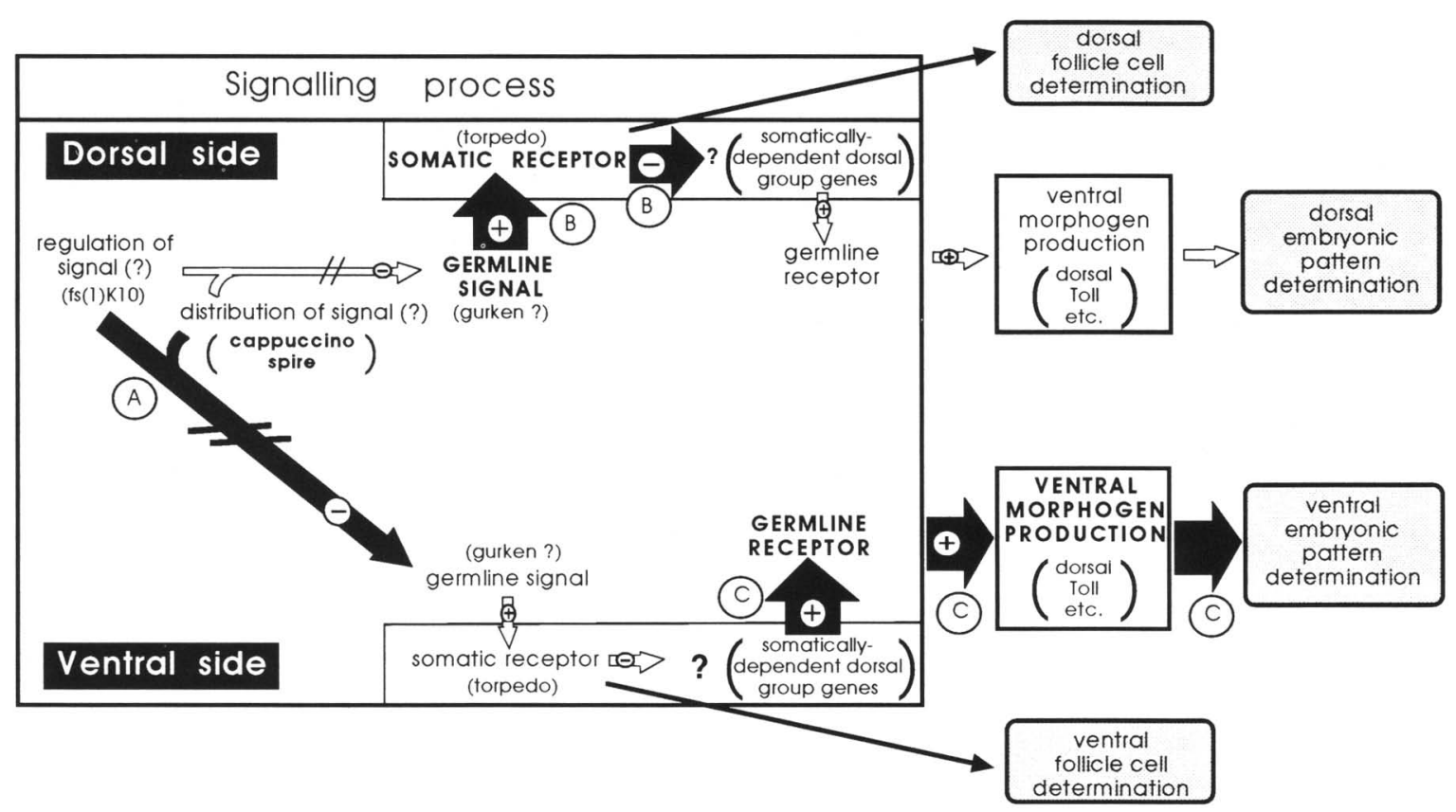

Figure 9. A working model for the early steps in dorsoventral patterning. This model combines the analysis of the mutant phenotypes, the epistatic relationships between the genes, the cell type in which the gene functions, and molecular information about the location and nature of the top and $f s(1) K 10$ gene products. Within the egg chamber there must be an initial dorsoventral asymmetry, the nature of which is unknown. On the ventral side of the oocyte, this asymmetry results in low activity levels of a signaling process between the somatically derived follicle cells and the germ-line-derived oocyte-nurse cell complex. In the absence of $f_{s}(1) K 10, c a p u$, or spir (blocking the pathway at $A$ ), the signaling process occurs at high levels on the ventral side of the egg chamber, resulting in dorsalization of the egg and embryo. Because of its location within the oocyte nucleus and the presence of a DNA recognition helix (Proust et al. 1988), the $f_{s}(1) K 10$ gene product is a good candidate for negatively regulating expression of the germ-line signal, either directly or through the action of intermediate genes. We suggest that capu and spir might be involved in establishing or maintaining the proper spatial distribution of the germ-line signal (again either directly or indirectly) by analogy to their proposed role in anteroposterior patterning (see Discussion). Because top functions in the soma (Schüpbach 1987) and encodes the Drosophila homolog of the EGF receptor (Price et al. 1989; Schejter and Shilo 1989), it is thought to have a direct role in the intercellular signaling process, probably as the somatic receptor for the germ-line signal. Both grk and top mutant females produce ventralized eggs and embryos (block at $B$ ). Because grk functions in the germ line and directs behavior of the follicle cells (Schüpbach 1987), it is probably directly or indirectly involved in the production of the germ-line signal. The high levels of the intercellular signaling activity on the dorsal side of the egg chamber result in dorsal-type follicle cell determination and in the ultimate repression of production of the ventral morphogen on the dorsal side of the egg. Because top acts in the soma but regulates ventral morphogen production in the egg, activation of top has to be signaled back to the germ line. There are additional members of the dorsal group of maternal-effect genes that act in the soma ( $T$. Schüpbach, unpubl.; C. Nüsslein-Volhard, pers. comm.). The function of these genes is unknown, but they might be involved in modification of the somatic signal and/or transmission of the somatic signal back to the germ line. The repressing effect on ventral morphogen production by top on the dorsal side then occurs before the action of these genes, before the signal is transmitted back to the germ line. On the ventral side of the egg chamber, the low level of the intercellular signaling process results in ventral-type follicle cell determination and high levels of ventral morphogen. The germ line-dependent genes of the dorsal-Toll group are responsible for the production of ventral morphogen. Blocking the pathway at $C$ results in the production of dorsalized embryos in wild-type eggshells. For the purposes of simplification, the model shows extremes of expression that probably exist only at the dorsal-most and ventral-most regions of the dorsoventral axis. We expect that, in reality, the levels of activity are graded along the axis.

segmentation in the anterior half of a bicaudal embryo. Because normal abdominal segments form in the double mutant, capu and spir do not seem to be involved primarily in the production of the abdominal segmentation determinant. It has been shown that the posterior cytoplam of a Drosophila egg contains the determinant for abdominal segmentation, as well as the polar granules (Frohnhöfer 1986; Lehmann and Nüsslein-Volhard 1986). Bic- $D$ most likely misplaces posterior determinants to the anterior end of the egg (Frohnhöfer 1986; Lehmann and Nüsslein-Volhard 1986). In the Bic-D double mutants, Bic-D is probably still causing misloca- tion of the abdominal segmentation determinant to the anterior pole, thus circumventing the requirement for capu and spir in abdominal segmentation at the anterior end of the bicaudal embryo. This line of reasoning suggests two alternative models for how normal abdominal segmentation occurs in the anterior half of the bicaudal embryo. In the first model, the capu and spir gene products normally might be involved in transporting the abdominal segmentation determinant (and possibly also components of the polar granules) to (or stabilizing it at) the posterior pole. By causing localization and/or stabilization of the posterior determinant in the anterior of the 
oocyte, Bic- $D$ directly circumvents the requirement for the capu and spir gene products, resulting in normal abdominal segmentation in the anterior half of the egg. In an alternate model, capu and spir gene products normally might be involved in activation or utilization of the posterior determinant, but the anterior half of the egg contains gene products that can substitute for this function, resulting in normal abdominal segmentation in the anterior of a bicaudal egg. However, because the vasa antibody staining indicates that vasa protein is not concentrated in the posterior plasm in capu and spir oocytes, we believe the first model is more reasonablethat capu and spir gene products are required for localization or stabilization of substances at the posterior pole of the egg chamber.

If capu and spir are involved directly in localization or stabilization of substances to the posterior pole of the oocyte for anteroposterior patterning, it would seem most reasonable to propose that they act similarly in dorsoventral patterning. There are no visible, asymmetrically localized structures in the oocyte or embryo that are thought to be involved in specifying pattern along the dorsoventral axis. However, the Drosophila embryo does not develop randomly in the egg but always has its dorsoventral pattern aligned with that of the eggshell. Therefore, the embryonic dorsoventral axis is also already predetermined in oogenesis, and some factor or structure must be asymmetrically distributed dorsoventrally. The earliest visible dorsoventral asymmetry in the oocyte during oogenesis is the asymmetric localization of the oocyte nucleus. Parks and Spradling (1987) observed dorsoventral asymmetries in expression of chorion genes during stage 10B of oogenesis. Follicle cells situated over the oocyte nucleus in the dorsal anterior region of the oocyte express certain chorion genes earlier than other follicle cells. These investigators suggest that given the proximity of these follicle cells to the oocyte nucleus, a signal from the oocyte nucleus to the follicle cells may be responsible for establishing this asymmetric chorion gene expression. As discussed above, a similar asymmetric signal from the oocyte might establish the dorsoventral pattern of the eggshell and embryo, possibly through the action of grk and top. Therefore, capu and spir might be involved in the localization or stabilization of asymmetric substances that are necessary for the production of any of these dorsoventral asymmetries.

According to this model, the phenotypic variability observed for capu and spir could be explained as different sensitivities in the dorsoventral and anteroposterior axes to loss of a transport system. Because even the weakest alleles cause failure of polar granule formation and some abdominal segmentation defects, the anteroposterior axis would have to be considered more sensitive to loss of the asymmetric distribution of substances. Because dorsoventral pattern defects become frequent only in the stronger alleles, the dorsoventral axis may be less sensitive either because the distances involved are shorter or because substances do not have to be as tightly localized for proper function. This also might explain the variation in dorsalization seen in the mutants.

It is possible that capu and spir might function by simultaneously regulating members of the grandchildless-knirps and dorsalizing groups of loci. Because staufen (Schüpbach and Wieschaus 1986) is the only identified member of the grandchildless-knirps group of loci to produce the same phenotype as capu and spir in combination with Bic-D (R. Lehmann, pers. comm.), staufen is the only candidate within this class of loci that could be regulated directly by capu and spir. It seems unlikely that capu and spir are regulating staufen, however, because capu and spir mutant embryos do not have the head defects typical of staufen mutant embryos. The possibility exists that there are additional, unidentified loci with the grandchildless-knirps mutant phenotype that would be better candidates for being regulated directly by capu and spir. Because of the similarities between the severely dorsalized capu and spir chorion and embryo phenotypes and the $f s(1) K 10$ phenotype, it is tempting to speculate that capu and spir might be regulating $f_{s}(1) K 10$ in the dorsoventral axis. The fs(1)K10 mutant phenotype, however, is not variable like that of capu and spir. This model would therefore suggest that mutations in capu and spir are not completely eliminating $f_{s}(1) K 10$ function but, rather, decreasing expression or function of $f_{s}(1) K 10$.

\section{Materials and methods}

\section{Genetics}

Three alleles of capu and four of spir were isolated in a screen for female steriles on the second chromosome (Schüpbach and Wieschaus 1989). Six alleles of spir were isolated fortuitously in a similar screen for female sterile mutations on the third chromosome in the laboratory of C. Nüsslein-Volhard. Two alleles of spir and one of capu were isolated by R. Clifford in a screen for mutations causing lethality or female sterility in combination with a chromosome carrying $s^{2} i^{R P}$ and $c a p u^{R K}$. All alleles were induced with ethylmethane sulfonate (EMS), except for $\mathrm{capu}^{G 7}$, which was induced with $\gamma$-rays.

The map position of $c a p u^{R K}$ was found to be $2-8$, whereas that of spirRP was found to be $2-54.5$. The deficiency used to uncover capu, $D f(2 L)$ ed $^{S Z 1.2}$ (Reuter and Szidonya 1983; Semeshin and Szidonya 1985), is deleted for the region between 24A3-4 and 24D3-4, whereas those used to uncover spir are $D f(2 L) S D-72^{\text {pr26, }}$ which is deficient from $37 \mathrm{D} 5-6$ to $38 \mathrm{C} 8-10$, and Df/2L/SD-72pr21, which is deficient from 37E3-F1 to 38C6-10 (Brittnacher and Ganetzky 1983).

\section{Characterization of mutant phenotype}

For microscopic examination of chorions and embryonic cuticular phenotypes, eggs and embryos were treated as in Wieschaus and Nüsslein-Volhard (1986). Embryos were prepared for sectioning as in Schüpbach and Wieschaus (1986). Egg chambers were stained with rhodamine-conjugated phalloidin or prepared for DIC as described for embryos in Wieschaus and Nüsslein-Volhard (1986). Follicle cell imprints and nuclear densities were counted using a Mac II and Image 1.03 image analysis software designed by Wayne Rasband. Eggs with the most severe dorsalized phenotype were selected from spir and capu and compared to eggs from wild type. All visible imprints 
on both surfaces were counted, but because of the spherical nature of the egg, it is not possible to count follicle cell imprints on the edges of the surface. Nuclear densities were counted in embryos stained with fuchsin, as described in Wieschaus and Nüsslein-Volhard (1986). Defects during cellularization have

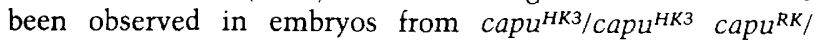

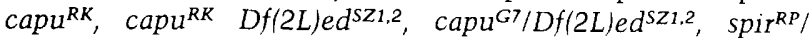

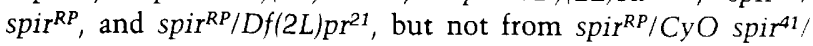
spir $^{A 1}$ or $\mathrm{Capu}^{G 7 / C y O}$.

\section{Immunocytochemistry}

Ovaries were prepared for cryostat sectioning as described for embryos in Hafen et al. (1983), except that $0.1 \mathrm{M}$ phosphate buffer $(\mathrm{pH} 7.6)$ was used instead of phosphate-buffered saline (PBS). Sections were 12- to $15-\mu \mathrm{m}$ thick. Subsequent treatment of the sections and immunostaining of the ovary sections with the polar granule antibody (mAb 46F11) was conducted as in Hay et al. (1988b), using a $1: 500$ dilution of affinity-purified antibody (kindly provided by B. Hay). Embryos were stained with this antibody, as described in Hay et al. (1988b). Embryos for zen and $\beta$-galactosidase antibody staining were dechorionated in bleach, fixed in a mixture of $9: 1$ heptane $/ 3.7 \%$ formaldehyde in PBS for $5 \mathrm{~min}$, and devitellinized using the modification of the Mitchison and Sedat (1983) procedure described in Wieschaus and Nüsslein-Volhard (1986). After rehydration through a series of solutions containing decreasing concentrations of alcohol, the embryos were incubated overnight at $4^{\circ} \mathrm{C}$ with the antibody. The zen antibody (kindly provided by Chris Rushlow) was diluted $1: 20$, the antibody against $\beta$-galactosidase (Promega) was diluted $1: 1000$, and the polar granule antibody (kindly provided by B. Hay) was diluted $1: 5$. Antibody localization was visualized using a Vectastain kit (Vectastain peroxidase $A B C$ kit, Vector Labs)-either with biotinylated goat anti-mouse ( $\beta$-galactosidase, polar granules) or biotinylated goat anti-rabbit (zen) avidin-horseradish peroxidase-complexed antibody. Stained embryos were then dehydrated through an increasing methanol series and mounted on glass slides in methyl salicylate for observation.

\section{Germ-line mosaics}

Pole cell transplants were conducted as described in Van Deusen (1976). Crosses used to generate pole cell donors for capu were $\mathrm{capu}^{R K} \mathrm{cn} \mathrm{bw/CyO} \& \times \mathrm{capu}^{R K} \mathrm{cn} b w / \mathrm{capu}^{R K}$ cn bw $\delta$, and for spir were spir ${ }^{03} / \mathrm{CyO} \& \times$ spir $^{03} /$ spir $^{03} \delta$. The cross used to generate recipients was y $\mathrm{f}$ mally $\vee \mathrm{f} \mathrm{mal}$ $q \times o v O^{D 1} v \mathrm{mal} / \mathrm{Y} \delta$. The recipient females carry ovo ${ }^{D 1}$, a dominant germ-line-dependent female sterile mutation that prevents development of the female germ line (Busson et al. 1983; Perrimon and Gans 1983; Oliver et al. 1987). Thus, only successfully transplanted pole cells will produce eggs. Adult recipient females were mated with the following test partners: for

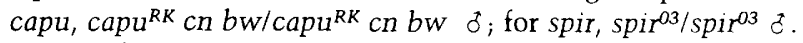

Germ-line mosaics were also induced by irradiation of larvae transheterozygous for FS(2)1 (Macdonald and Struhl 1986) and either $c a p u^{R K}$ or $s p i r^{P I}$, as in the dominant female sterile technique (Wieschaus 1980). Larvae that were $40 \pm 6$ hr were irradiated with $\sim 1300 \gamma$-rays. Females carrying Fs(2)1 produce very small, abnormal eggs. Females carrying clones of germ-line cells that had lost $F s(2) 1$ (and thus, are homozygous for capu or spirl iay normal-size eggs.

\section{Acknowledgments}

We thank Dari Sweeton for her excellent technical assistance with the electron microscopy work. We also thank Ruth Lehmann and Christiane Nüsslein-Volhard for providing us with additional spir alleles and Barry Ganetzky and Gunther Reuter for providing us with deficiency stocks. We are grateful to Chris Rushlow for supplying us with zen antibody, Sigfried Roth for the twist antibody, and Bruce Hay for the vasa antibody. We thank Wayne Rasband at the National Institutes of Health (NIH) for making available the image analysis software used for this study. In addition, we are grateful to our colleagues Will Boorstein, Ross Cagan, Bob Clifford, Kate Harding, Suki Parks, Mark Peifer, Marya Postner, Jim Price, Lesilee Simpson, and Eric Wieschaus for their advice, support, helpful discussions, and reading of the manuscript. The electron microscope facility in the Biology Department at Princeton University was used for this study. This work was supported by an NIH postdoctoral fellowship (5 F32 GM-11404-02 BI-7) to L.J.M., and by a National Science Foundation grant (DCB-8505917) and an NIH grant (GM-40558-01) to T.S.

\section{References}

Akam, M. 1987. The molecular basis for metameric pattern in the Drosophila embryo. Development 101: 1-22.

Anderson, K.V. 1987. Dorsal-ventral embryonic pattern genes of Drosophila. Trends Genet. 3(4): 91-97.

Boswell, R.E. and A.P. Mahowald. 1985. tudor, a gene required for assembly of the germ plasm in Drosophila melanogaster. Cell 43: 97-104.

Brittnacher, J. and B. Ganetzky. 1983. On the components of segregation distortion in Drosophila melanogaster. II. Deletion mapping and dosage analysis of the SD locus. Genetics 103: $659-673$.

Busson, D., M. Gans, K. Komitopoulo, and M. Masson. 1983. Genetic analysis of three dominant female sterile mutations located on the X-chromosome of Drosophila melanogaster. Genetics 105: 309-325.

Carroll, S.B. and M.P. Scott. 1985. Localization of the fushi tarazu protein during Drosophila embryogenesis. Cell 43: $47-57$.

Carroll, S., G. Winslow, T. Schüpbach, and M. Scott. 1986. Maternal control of Drosophila segmentation gene expression. Nature 323: 278-280.

Carroll, S., G. Winslow, V. Twombly, and M. Scott. 1987. Genes that control dorsoventral polarity affect gene expression along the anteroposterior axis of the Drosophila embryo. Development 99: 327-332.

Degelmann, A., P.A. Hardy, N. Perrimon, and A.P. Mahowald. 1986. Developmental analysis of the torso-like phenotype in Drosophila produced by a maternal-effect locus. Dev. Biol. 115: 479-489.

Doyle, H.J., K. Harding, T. Hoey, and M. Levine. 1986. Transcripts encoded by a homeobox gene are restricted to dorsal tissues of Drosophila embryos. Nature 323: 76-79.

Driever, W. and C. Nüsslein-Volhard. 1988a. A gradient of bicoid protein in Drosophila embryos. Cell 54: 83-93.

- 1988b. The bicoid protein determines position in the Drosophila embryo in a concentration-dependent manner. Cell 54: 95-104.

Frohnhöfer, H.G. and C. Nüsslein-Volhard. 1986. Organization of anterior pattern in the Drosophila embryo by the maternal gene bicoid. Nature 324: 120-125.

1987. Maternal genes required for the anterior localization of bicoid activity in the embryo of Drosophila. Genes Dev. 1: $880-890$. 
Frohnhöfer, H.G., R. Lehmann, and C. Nüsslein-Volhard. 1986. Manipulating the anteroposterior pattern of the Drosophila embryo. I. Embryol. Exp. Morphol. 97S: 169-179.

Hafen, E., A. Kuriowa, and W. Gehring. 1984. Spatial distribution of transcripts from the segmentation gene fushi tarazu during Drosophila embryonic development. Cell 37: 833841.

Hafen, E., M. Levine, R.L. Garber, and W.J. Gehring. 1983. An improved in situ hybridization method for the detection of cellular RNAs in Drosophila tissue sections and its application for localizing transcripts of the homeotic Antennapedia gene complex. EMBO I. 2(4): 617-623.

Hay, B., L.Y. Jan, and Y.M. Jan. 1988a. A protein component of Drosophila polar granules is encoded by vasa and has extensive sequence similarity to ATP-dependent helicases. Cell 55: $577-587$.

Hay, B., L. Ackerman, S. Barbel, L. Jan, and Y. Jan. 1988b. Identification of a component of Drosophila polar granules. Development 103: 625-640.

Hiromi, Y., A. Kuroiwa, and W. Gehring. 1985. Control elements of the Drosophila segmentation gene fushi tarazu. Cell 43: 603-613.

Ingham, P.W. 1988. The molecular genetics of embryonic pattern formation in Drosophila. Nature 335: 25-34.

King, R.C. 1970 . Ovarian development in Drosophila melanogaster. Academic Press, New York.

Klingler, M., M. Erdelyi, J. Szabae, and C. Nüsslein-Volhard. 1988. Function of torso in determining the terminal anlagen of the Drosophila embryo. Nature 335: 275-277.

Lehmann, R. 1985. 'Regionsspezifische segmentierungsmutanten bei Drosophila melanogaster meigen.' PhD. thesis. Eberhard-Karls-Universitat, Tubingen.

- 1988. Phenotypic comparison between maternal and zygotic genes controlling the segmental pattern of the Drosophila embryo. Development 104s: 17-27.

Lehmann, R. and C. Nüsslein-Volhard. 1986. Abdominal segmentation, pole cell formation, and embryonic polarity require the localized activity of oskar, a maternal gene in Drosophila. Cell 47: 141-152.

-1987. Involvement of the pumilio gene in the transport of an abdominal signal in the Drosophila embryo. Nature 329: $167-170$.

Levine, M. 1988. Molecular analysis of dorsal-ventral polarity in Drosophila. Cell 52: 785-786.

Macdonald, P.M. and G. Struhl. 1986. A molecular gradient in early Drosophila embryos and its role in specifying the body pattern. Nature 324: 537-545

Mahowald, A.P., C.D. Allis, K.M. Karrer, E.M. Underwood, and G.L. Waring. 1979. Germ plasm and pole cells of Drosophila. In Determinants of spatial organization. (ed. S. Subtelney and I.R. Koenigsberg) p. 127-146. Academic Press, New York.

Mitchison, T.J. and J. Sedat. 1983. Localization of antigenic determinants in whole Drosophila embryos. Dev. Biol. 99: $261-264$.

Mohler, J. and E.F. Wieschaus. 1985. Bicaudal mutations of Drosophila melanogaster: Alteration of blastoderm cell fate. Cold Spring Harbor Symp. Quant. Biol. 50: 105-111.

- 1986. Dominant maternal-effect mutations of Drosophila melanogaster causing the production of double-abdomen embryos. Genetics 112: 803-822.

Nüsslein-Volhard, C. 1979. Maternal effect mutations that alter the spatial coordinates of the embryo of Drosophila melanogaster. In Determinants of spatial organization. (ed. S. Subtelney and I.R. Koenigsbergl, pp. 185-211. Academic Press, New York.
Nüsslein-Volhard, C., H.G. Frohnhöfer, and R. Lehmann. 1987. Determination of anteroposterior polarity in Drosophila. Science 238: 1675-1681.

Oliver, B., N. Perrimon, and A.P. Mahowald. 1987. The ovo locus is required for sex-specific germ line maintenance in Drosophila. Genes Dev. 1: 913-923.

Parks, S. and A. Spradling. 1987. Spatially regulated expression of chorion genes during Drosophila oogenesis. Genes Dev. 1: $497-509$.

Perrimon, N. and N. Gans. 1983. Clonal analysis of the tissue specificity of recessive female-sterile mutation Fs(1)K1237. Dev. Biol. 105: 404-414.

Price, J.V., R.J. Clifford, and T. Schüpbach. 1989. The maternal ventralizing locus torpedo is allelic to faint little ball, an embryonic lethal, and encodes the Drosophila EGF receptor homolog. Cell 56: 1085-1092.

Proust, E., F. Deryckere, C. Roos, M. Haenlin, V. Pantesco, and E. Mohier. 1988. Role of the oocyte nucleus in determination of the dorsoventral polarity of Drosophila as revealed by molecular analysis of the Kl0 gene. Genes Dev. 2: 891900.

Reuter, G. and J. Szidonya. 1983. Cytogenetic analysis of variegation suppressors and dominant temperature-sensitive lethal in region 23-26 of chromosome $2 \mathrm{~L}$ in Drosophila melanogaster. Chromosoma 88: 277-285.

Rushlow, C., M. Frasch, H. Doyle, and M. Levine. 1987. Maternal regulation of zerknullt: A homeobox gene controlling differentiation of dorsal tissues in Drosophila. Nature 330: $583-586$

St. Johnston, R.D. and W.M. Gelbart. 1987. Decapentaplegic transcripts are localized along the dorsal-ventral axis of the Drosophila embryo. EMBO 1. 6(9): 2785-2791.

Schejter, E.D. and B. Shilo. 1989. The Drosophila EGF receptor homolog (DER) gene is allelic to faint little ball, a locus essential for embryonic development. Cell 56: 1093-111-4.

Schüpbach, T. 1987. Germline and soma cooperate during oogenesis to establish the dorso-ventral pattern of egg shell and embryo in Drosophila melanogaster. Cell 49: 699-707.

Schüpbach, T. and E. Wieschaus. 1986. Maternal-effect mutations altering the anterior-posterior pattern of the Drosophila embryo. Wilhelm Roux's Arch. Dev. Biol. 195: 302317.

1989. Female sterile mutations on the second chromosome of Drosophila melanogaster. I. Maternal effect mutations. Genetics 121: 101-117.

Scott, M. and P.H. O'Farrell. 1986. Spatial programming of gene expression in early Drosophila embryogenesis. Annu. Rev. Cell Biol. 2: 49-80.

Semeshin, V.F. and J. Szidonya. 1985. EM mapping of rearrangements in the 24-25 sections of $D$. melanogaster $2 \mathrm{~L}$ chromosomes. Dros. Inf. Serv. 61: 148-154.

Steward, R., S.B. Zusman, L.H. Huang, and P. Schedl. 1988. The dorsal protein is distributed in a gradient in early Drosophila embryos. Cell 55: 487-495.

Strecker, T.R., S.R. Halsell, W.W. Fisher, and H.D. Lipschitz. 1989. Reciprocal effects of hyper-and hypoactivity mutations in the Drosophila pattern gene torso. Science 243: $1062-1066$.

Sullivan, W. 1987. Independence of fushi tarazu expression with respect to cellular density in Drosophila embryos. $\mathrm{Na}$ ture 327: 164-167.

Szabad, J., M. Erdelyi, and J. Szidonya. 1987. Characterization of FS(2)1, a germ-line dependent dominant female sterile mutation of Drosophila. Acta Biol. Hun. 38(2): 257-266.

Thisse, B., C. Stoetzel, C. Gorostiza-Thisse, and F. PerrinSchmitt. 1988. Sequence of the twist gene and nuclear local- 
ization of its protein in endomesodermal cells of early Drosophila embryos. EMBO J. 7(7): 2175-2183.

Van Deusen, E.B. 1976. Sex determination in germ line chimeras of Drosophila melanogaster. J. Embryol. Exp. Morphol. 37: 173-185.

Wieschaus, E. 1979. $f_{S}(1) K 10$, a female sterile mutation altering the pattern of both the egg coverings and the resultant embryos in Drosophila. In Cell lineage, stem cell and cell differentiation (ed. N. LeDouarin), pp. 291-302, Elsevier/ North-Holland Biomedical Press, New York.

A combined genetic and mosaic approach to the study of oogenesis in Drosophila. Development and neurobiology of Drosophila, (ed. O. Siddiqi, P. Babu, L.M. Hall, and I.C. Hall), pp. 85-94, Plenum Publishing, New York.

Wieschaus, E. and C. Nüsslein-Volhard. 1986. Looking at embryos. Drosophila: A practical approach. (ed. D.B. Roberts), pp. 199-228, IRL Press, Oxford, Washington D.C.

Wieschaus, E. and J. Szabad. 1979. the development and function of the female germ line in Drosophila melanogaster: A cell lineage study. Dev. Biol. 68: 29-46.

Wieschaus, E., J.L. Marsh, and W. Gehring. 1978. fs(1)K10, a germline-dependent female sterile mutation causing abnormal chorion morphology in Drosophila melanogaster. Wilhelm Roux's Arch. Dev. Biol. 184: 75-82.

Zalokar, M. and I. Erk. 1976. Division and migration of nuclei during early embryogenesis of Drosophila melanogaster. I. Microsc. Biol. Cell 25: 97-106.

Zusman, S.B. and E. Wieschaus. 1987. A cell marker system and mosaic patterns during early embryonic development in Drosophila melanogaster. Genetics 115: 725-736. 


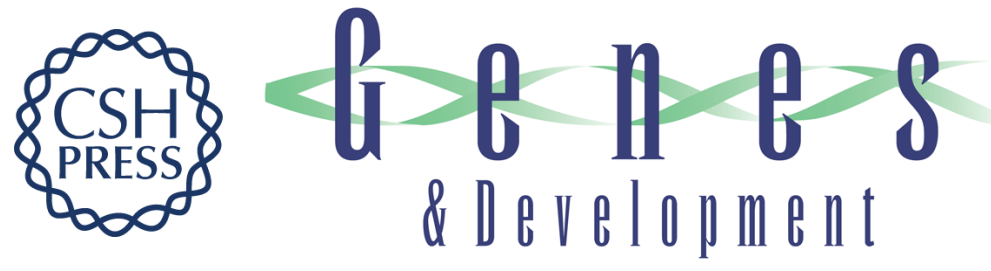

\section{cappuccino and spire: two unique maternal-effect loci required for both the anteroposterior and dorsoventral patterns of the Drosophila embryo.}

L J Manseau and T Schüpbach

Genes Dev. 1989, 3:

Access the most recent version at doi:10.1101/gad.3.9.1437 $\begin{array}{ll}\text { References } & \text { This article cites } 55 \text { articles, } 16 \text { of which can be accessed free at: } \\ \text { http://genesdev.cshlp.org/content/3/9/1437.full.html\#ref-list-1 }\end{array}$

License

Email Alerting Service

Receive free email alerts when new articles cite this article - sign up in the box at the top right corner of the article or click here.

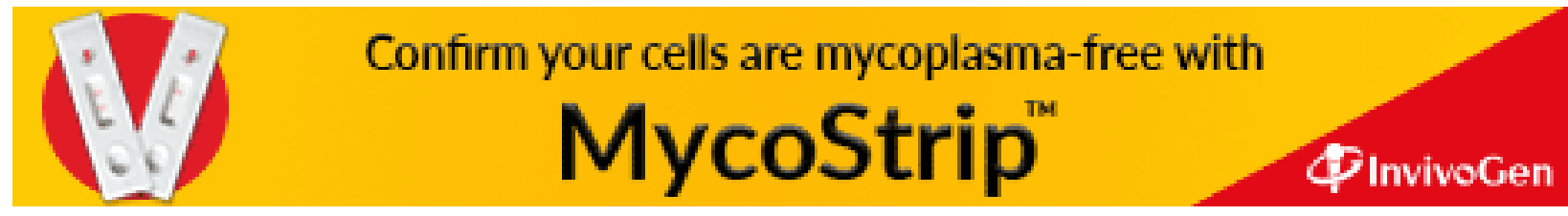

